\title{
PREGNANCY OUTCOME AND FERTILITY CONTROL IN ABERDEEN
}

\author{
BARBARA THOMPSON* AND JEAN AITKEN-SWAN \\ MRC Medical Sociology Unit, University of Aberdeen
}

In Aberdeen the birth-rate fell from $17 \cdot 6$ in 1961 to its lowest level, $14 \cdot 1$, in 1969 and then rose slightly to $14 \cdot 7$ in 1971 (Medical Officer of Health Report, 1971). From the mid-sixties birth-rates generally were falling in Britain and in other western societies affected by similar demographic and socio-economic forces but Aberdeen's rate fell to a lower level than that of England and Wales $(16 \cdot 0)$ or of Scotland as a whole $(16 \cdot 6)$. There has been no deliberate policy in Aberdeen to aim for 'zero growth' but rather the objective has been that every woman should attain 'a fifth freedom-freedom from the tyranny of excessive fertility' (Baird, 1965). Thus birth control in all its aspects has long been accepted as an integral part of the maternity services. Aberdeen's reputation in this field has received much publicity, various aspects and particularly its policy on therapeutic abortion having been featured in television, radio, and the press. This article gives an overview and reports the outcome of pregnancies and the use of the family planning clinic and sterilization in Aberdeen City residents during the decade 1961-71 during which oral contraception was introduced (1964), the Abortion Act came into force (1968), and sterilization increased, particularly vasectomy.

Aberdeen, with a relatively unchanging population of 183,000 is a well-defined city set in a predominantly rural area. The opportunities it provided for the development of a comprehensive maternity service were perceived many years ago by $\mathrm{Sir}$ Dugald Baird. Under his leadership as Professor of Obstetrics and Gynaecology from 1936, and that of his successor, Professor Ian MacGillivray, from 1965, the maternity service in Aberdeen has evolved. Baird (1969b) has described its development and the collaboration between hospital and local authority which has been a feature of it. The coordination of the various parts of the service and consequent centralization of treatment and records facilitate

* Reprint requests to Dr. B. Thompson, Centre for Social Studies, Westburn Road, Aberdeen AB9 2ZE. research, especially epidemiological and social research in obstetrics, gynaecology, and birth control.

From 1948 Aberdeen Maternity Hospital has maintained records of all births whether in hospital, private accommodation, or at home. The number of private maternity patients has declined (151 in $1961 ; 27$ in 1971) and domiciliary practice has virtually disappeared (one booked patient in 1971). Most therapeutic abortions take place entirely within the National Health Service. The remainder are performed either in the private ward of the general hospital or in the city's only nursing home, but details of private patients are not available. Evidence from completed obstetric histories and from discussions with general practitioners suggests that the vast majority of women aborting spontaneously are admitted to hospital for observation or curettage and it is believed that criminal abortion is rare. Accurate information is therefore available on nearly all pregnancies to Aberdeen women.

Present practice has evolved gradually over many years. For example, female sterilization started in a small way in the thirties in women aged 35 or over who might have had as many as eight or more children. In those days women, even those exhausted by childbearing, had to be persuaded that sterilization offered them the best means of controlling their fertility. At that time Aberdeen obstetricians were also taking advantage of the Common Law of Scotland which allowed a doctor acting in good faith to perform an abortion when this was thought to be in the patient's best interests. Between 1938 and 1947 nearly two-thirds of all women who underwent therapeutic abortion and concurrent sterilization had had seven or more pregnancies. By the late 1960 s over $40 \%$ of women each year having a fifth or later pregnancy had postpartum sterilization and another $3 \%$ were sterilized concurrently with therapeutic abortion by abdominal hysterotomy (Baird, 1971). Today many women in 
their middle twenties with small families put pressure on general practitioners and gynaecologists to agree to sterilization.

Aberdeen's Family Planning Clinic, which had started as a voluntary organization in the thirties, was taken over by the Town Council in 1946 to become Scotland's first local authority family planning service, the second in Britain. In 1964 its work began to expand, sessions were started at peripheral clinics, and in 1970 provision was made for a domiciliary service in special circumstances. The clinic has dispensed contraceptives without charge since 1966, and in 1971 the need for referral by an authorised person, usually a general practitioner, was abolished. Besides providing practical instruction and literature on contraception and giving a consultative and counselling service the clinic cooperates closely with the surgeons and gynaecologists who perform male and female sterilization.

This is the background against which trends in the outcome of pregnancy from 1961 to 1971 will now be considered. The Aberdeen material is unique in that rates are based on pregnancies and not on published statistics of numbers of births or fertile women.

The number of pregnancies to Aberdeen women in 1971 was 3,308 or $7 \cdot 8 \%$ fewer than in 1961 (Table I). In the same period births declined by $18 \%$.

TABLE I

OUTCOME OF PREGNANCIES IN 1961 AND 1971

\begin{tabular}{|c|c|c|c|c|}
\hline Year & & & 1961 & 1971 \\
\hline $\begin{array}{l}\text { Births } \\
\text { Spontaneous abortions } \\
\text { Therapeutic abortions }\end{array}$ & $\begin{array}{l}\because \\
\because \\
\therefore\end{array}$ & $\begin{array}{l}\cdots \\
\cdots \\
\cdots\end{array}$ & $\begin{array}{c}3,225 \\
295(16) \\
66\end{array}$ & $\begin{array}{l}\text { (ber) } \\
2,647 \\
283(2) \\
378\end{array}$ \\
\hline Total pregnancies ... & .. & .. & 3,586 & 3,308 \\
\hline
\end{tabular}

( ) Septic abortions

Spontaneous abortions occurred in about $8 \%$ of pregnancies in both 1961 and 1971 . The number of septic abortions, as defined by Milne (1971), fell from 16 in 1961 to 2 in 1971 and none was recorded in 1967. The most striking change was the sixfold increase in therapeutic abortions from $1 \cdot 8$ to $11 \%$ of all pregnancies. As numbers and outcome of pregnancy differ for legitimate and illegitimate pregnancies (defined according to marital state when the pregnancy ended), the two categories will be considered separately.

\section{Legitimate Pregnancies}

The number of legitimate pregnancies, 3,405 in 1961, fell below 3,000 for the first time in 1966,
TABLE II

OUTCOME OF LEGITIMATE PREGNANCIES

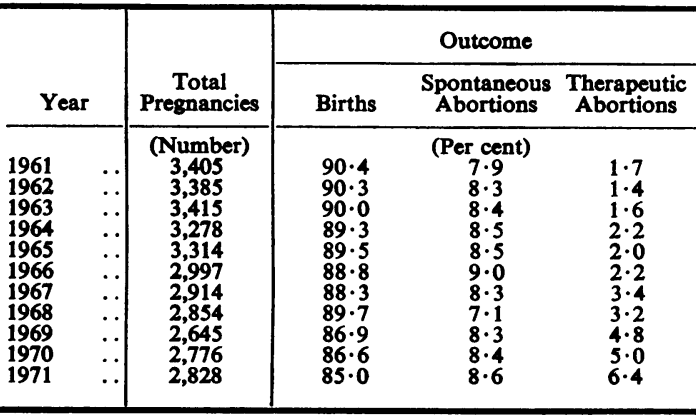

reached its lowest point $(2,645)$ in 1969 , and rose to 2,828 in 1971 (Table II). This rise may have been due at least partly to adverse publicity on oral contraception which undoubtedly deterred some women from taking the pill. As a proportion of all pregnancies, births fell from 90 to $85 \%$ due to the increase in therapeutic abortions, an increase which had already started before the Abortion Act came into force. Spontaneous abortions accounted for between 7 and $9 \%$ of pregnancies throughout the period.

Between 1961 and 1971 the proportion of womes having a fourth or later birth fell from 13 to $7 \%$ In the fifties interviews with women during their first pregnancy and again five years later showed that most wanted two children and none wanted more than four. At the second interview $10 \%$ said that they had more children than they had intended and could rear without excessive strain (Thompson and Illsley, 1969). Only $31 \%$ reported the regular use of appliance methods of contraception. The methods then available, especially the diaphragm, were unattractive or unacceptable to many. Before the mid-sixties few general practitioners gave advice on contraception and only a few multiparous women used the Family Planning Clinic. Between 1964, when oral contraception became available, and 1968 the number of women attending the clinic for the first time increased fivefold (Table III) and women now came to seek advice on postponing a first pregnancy. After a fall in new attendances at the time of the adverse publicity on the pill, numbers rose again. By 1970 half the Aberdeen Maternity Hospital patients had used oral contraceptives, most of them, however, having obtained supplies through their general practitioners. Very few women now attending the clinic choose the diaphragm. The intra-uterine device (IUD) has not been popular at the clinic 
TABLE III

FAMILY PLANNING CLINIC-MARRIED WOMEN NEW ATTENDERS FIRST QUARTER EACH YEAR 196472

\begin{tabular}{|c|c|c|c|c|c|c|c|c|c|c|c|c|}
\hline & & & & \multicolumn{9}{|c|}{ January-March } \\
\hline \multicolumn{4}{|c|}{ Contraceptive given } & 1964 & 1965 & 1966 & 1967 & 1968 & 1969 & 1970 & 1971 & 1972 \\
\hline $\begin{array}{l}\text { Diaphragm } \\
\text { Chemical } \\
\text { Oral } \\
\text { IUD }\end{array}$ & $\begin{array}{l}\ddot{ } \\
\cdots \\
\cdots\end{array}$ & $\begin{array}{l}\cdots \\
\cdots \\
\cdots\end{array}$ & $\begin{array}{l}\cdots \\
\cdots \\
\cdots\end{array}$ & $\begin{array}{r}48 \\
1 \\
- \\
\end{array}$ & $\begin{array}{r}29 \\
3 \\
90 \\
-\end{array}$ & $\frac{36}{83}$ & $\frac{14}{176}$ & $\frac{17}{266}$ & $\begin{array}{r}18 \\
1 \\
229 \\
-\end{array}$ & $\begin{array}{r}16 \\
10 \\
181 \\
3\end{array}$ & $\begin{array}{r}11 \\
6 \\
237 \\
12\end{array}$ & $\begin{array}{r}24 \\
10 \\
254 \\
7\end{array}$ \\
\hline Total marrie & wo & $\ldots$ & $\ldots$ & 49 & 122 & 123 & 236 & 290 & 248 & 210 & 266 & 295 \\
\hline
\end{tabular}

with either doctors or patients after trials in 1966-68 produced an unacceptably high rate of complications (bleeding, pain, expulsion, etc.) and anxiety in the women fitted with it. However, the IUD has always been available and chosen by some women or recommended to others. In addition, gynaecologists, but not general practitioners, fit IUDs.

There is growing concern that, in spite of the progress being made in the contraceptive services, the numbers of abortions continue to increase. This concern has expressed itself in the setting up of a working party comprising obstetricians, local authority and student health service medical officers, general practitioners, and sociologists to investigate the provision of contraception in north-east Scotland and to make recommendations for its improvement.

Limitation in numbers rather than spacing of children is the crucial problem for parents, and more wives, and now husbands, are seeking sterilization. Two and a half times as many women were sterilized in 1971 as in 1961 (Table IV). The increase was particularly rapid after 1969 when laparoscopic sterilization was introduced. Few vasectomies were performed before 1970 but in the two following years 319 were done under the National Health Service.

The increase in sterilization of both men and women who have three or fewer children confirms that most couples still want two children and very few want as many as four. Women are reluctant to take the pill indefinitely after they have achieved the number of children they want but are willing to take it for a few years until they are positive that their family is complete. Once a couple has decided on sterilization a consequence of delay in having it done may be an unwanted pregnancy. Few women regret having been sterilized but some regret not having been sterilized earlier (Thompson and Baird, 1969). It should be noted that more sterilizations are being performed in conjunction with terminations of pregnancy, $19 \%$ in $1962-67$ and $28 \%$ in 1968-70. One reason why some couples choose vasectomy is because it is usually performed three or four weeks after referral to the surgeon whereas the waiting time for female sterilization is about a year.

The proportion of sterilized women whose husbands are in non-manual occupations has shown a slight increase to about $18 \%$ (Table V). In comparison, $26.8 \%$ of vasectomized men are nonmanual workers. The inclusion of private patients would doubtless emphasize this trend.

\section{Illegitimate Pregnancies}

In $196165 \%$ of all illegitimate pregnancies were to women unmarried at the time of outcome of the pregnancy and the remainder were to women who

TABLE IV

NUMBER OF NHS STERILIZATIONS 1961-71

\begin{tabular}{|c|c|c|c|c|c|c|c|}
\hline & & & \multicolumn{3}{|c|}{ Wife: Sterilization } & \multirow{2}{*}{$\begin{array}{l}\text { Husband: } \\
\text { Vasectomy }\end{array}$} & \multirow[b]{2}{*}{ Total NHS Sterilizations } \\
\hline \multicolumn{3}{|c|}{ Year } & With Abortion & Not Pregnant & Total Women & & \\
\hline $\begin{array}{l}1961 \\
1962 \\
1963 \\
1964 \\
1965 \\
1966 \\
1967 \\
1968 \\
1969 \\
1970 \\
1971\end{array}$ & $\begin{array}{l}\cdots \\
\cdots \\
\cdots \\
\cdots \\
\cdots \\
\cdots \\
\cdots \\
\cdots\end{array}$ & $\begin{array}{c}. . \\
\cdots \\
\cdots \\
\cdots \\
\cdots \\
\cdots \\
\cdots \\
\cdots \\
.\end{array}$ & $\begin{array}{r}44 \\
45 \\
43 \\
52 \\
41 \\
34 \\
69 \\
74 \\
92 \\
111 \\
118\end{array}$ & $\begin{array}{l}157 \\
153 \\
205 \\
204 \\
192 \\
201 \\
199 \\
223 \\
188 \\
287 \\
411\end{array}$ & $\begin{array}{l}201 \\
198 \\
248 \\
256 \\
233 \\
235 \\
268 \\
297 \\
280 \\
398 \\
529\end{array}$ & $\begin{array}{r}- \\
- \\
- \\
- \\
2 \\
4 \\
8 \\
149 \\
170\end{array}$ & $\begin{array}{l}201 \\
198 \\
248 \\
256 \\
233 \\
235 \\
270 \\
301 \\
288 \\
547 \\
699\end{array}$ \\
\hline
\end{tabular}


TABLE V

PERCENTAGE OF STERILIZED WOMEN AND MEN WITH CERTAIN CHARACTERISTICS

\begin{tabular}{|c|c|c|c|c|}
\hline Year & & $\begin{array}{l}3 \text { or Fewer } \\
\text { Surviving } \\
\text { Children }\end{array}$ & $\begin{array}{c}\text { Wife aged } \\
<30 \mathrm{yr}\end{array}$ & $\begin{array}{c}\text { Husband } \\
\text { Non-manual } \\
\text { Occupation }\end{array}$ \\
\hline $\begin{array}{l}1962-64 \\
1965-67 \\
1968-70\end{array}$ & $\begin{array}{l}. . \\
. .\end{array}$ & $\begin{array}{c}\text { Women } \\
34 \cdot 9 \\
36 \cdot 2 \\
55 \cdot 1\end{array}$ & $\begin{array}{l}42 \cdot 7 \\
36 \cdot 1 \\
37 \cdot 9\end{array}$ & $\begin{array}{l}16 \cdot 8 \\
18 \cdot 0 \\
17 \cdot 5\end{array}$ \\
\hline $1970-71$ & .. & $\begin{array}{l}\text { Men } \\
82 \cdot 0\end{array}$ & $31 \cdot 9$ & $26 \cdot 8$ \\
\hline
\end{tabular}

were divorced, separated or widowed. By 1971 the proportion to unmarried women had increased to $83 \%$, and the numbers had risen from 117 to 397 in the 11 years. Numbers to divorced, separated or widowed women rose less sharply from 64 to 84 .

The remarkable decrease in the proportion of illegitimate pregnancies ending in birth is accounted for by the rise in therapeutic abortions, a trend already well established by the time the Abortion Act came into force (Table VI). In the early sixties the percentage of illegitimate pregnancies being terminated-about $6 \%$-was three times as high as in legitimate pregnancies. From 1965 there was a marked and consistent increase in the proportion of therapeutic abortions until 1970 when over $45 \%$ of illegitimate pregnancies were being terminated. That year for the first time the number of therapeutic abortions (194) exceeded the number of illegitimate births (189). 1971 showed a fall in the proportion of therapeutic abortions, with one pregnancy in two continuing to an illegitimate birth.

Spontaneous abortion occurred in a higher proportion of illegitimate than legitimate pregnancies, being about double the legitimate rate until 1966. After this the illegitimate abortion rate fell to $8 \%$ in 1971 , similar to the rate for legitimate pregnancies. It is probable that in recent years some

TABLE VI

OUTCOME OF ILLEGITIMATE PREGNANCIES

\begin{tabular}{|c|c|c|c|c|c|}
\hline \multirow[b]{2}{*}{ Year } & & \multirow[b]{2}{*}{$\begin{array}{c}\text { Total } \\
\text { Pregnancies }\end{array}$} & \multicolumn{3}{|c|}{ Outcome } \\
\hline & & & Births & $\begin{array}{c}\text { Spontaneous } \\
\text { Abortions }\end{array}$ & $\begin{array}{c}\text { Therapeutic } \\
\text { Abortions }\end{array}$ \\
\hline $\begin{array}{l}1961 \\
1962 \\
1963 \\
1964 \\
1965 \\
1966 \\
1967 \\
1968 \\
1969 \\
1970 \\
1971\end{array}$ & $\begin{array}{l}\cdots \\
\cdots \\
\cdots \\
\cdots \\
\cdots \\
\cdots \\
\cdots \\
\cdots\end{array}$ & $\begin{array}{c}\text { (Number) } \\
181 \\
192 \\
223 \\
213 \\
262 \\
290 \\
329 \\
387 \\
432 \\
428 \\
480\end{array}$ & $\begin{array}{l}79 \cdot 6 \\
77 \cdot 6 \\
76 \cdot 7 \\
76 \cdot 6 \\
71 \cdot 4 \\
67 \cdot 5 \\
61 \cdot 4 \\
56 \cdot 3 \\
50 \cdot 5 \\
44 \cdot 2 \\
50 \cdot 6\end{array}$ & $\begin{array}{c}\text { (Per cent) } \\
15 \cdot 4 \\
14 \cdot 6 \\
17 \cdot 0 \\
16 \cdot 8 \\
16 \cdot 4 \\
13 \cdot 1 \\
13 \cdot 1 \\
11 \cdot 3 \\
12 \cdot 0 \\
10.5 \\
8 \cdot 3\end{array}$ & $\begin{array}{r}5 \cdot 0 \\
7 \cdot 8 \\
6 \cdot 3 \\
6 \cdot 6 \\
12 \cdot 2 \\
19 \cdot 4 \\
25 \cdot 5 \\
32 \cdot 4 \\
37 \cdot 5 \\
45 \cdot 3 \\
41 \cdot 1\end{array}$ \\
\hline
\end{tabular}

pregnancies were terminated which otherwise would have ended in spontaneous, self-induced or even criminal abortion.

The circumstances and social characteristics of women referred for consideration of abortion in Aberdeen have been described in a recent study (Horobin, 1973). Here we present what happens to all first pregnancies conceived outside marriage whatever the outcome, and how this outcome differs in women in different occupational groups.

In 1961 one in nearly four first pregnancies, whether legitimate or illegitimate at the time of outcome, were to women unmarried at conception. This proportion rose steadily until by 1971 about one in two first pregnancies had been conceived outside marriage. Faced with pregnancy the unmarried woman has three alternatives-to marry and continue the pregnancy (prenuptial conception), to continue the pregnancy unmarried, or to seek an abortion. In $1963-64$ over $70 \%$ of the women married before the birth of the baby. It was this group which was most affected by the increase in abortions. As the decade advanced there was a steady fall in the proportion of prenuptial conceptions. In contrast the rise in abortions does not seem to have affected illegitimate births so obviously Each year in spite of the rise in abortions the proportion of first pregnancies ending in an illegitio mate birth has remained at between 22 and $25 \%$ (Fig. 1).

Although Aberdeen's 'liberal' abortion policy appears to have had the effect of reducing the proportion of prenuptial conceptions rather than of

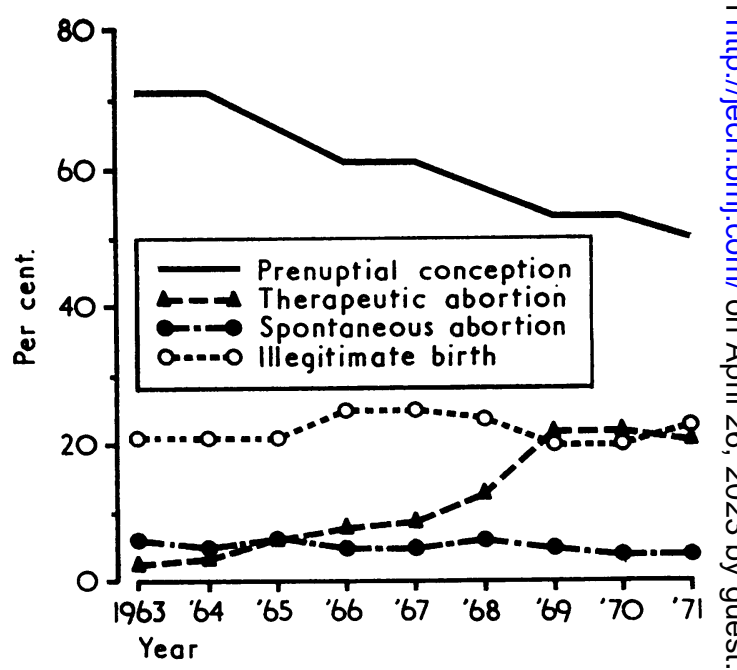

FiG. 1. Outcome of first pregnancies to women single at conception 1963-71. 

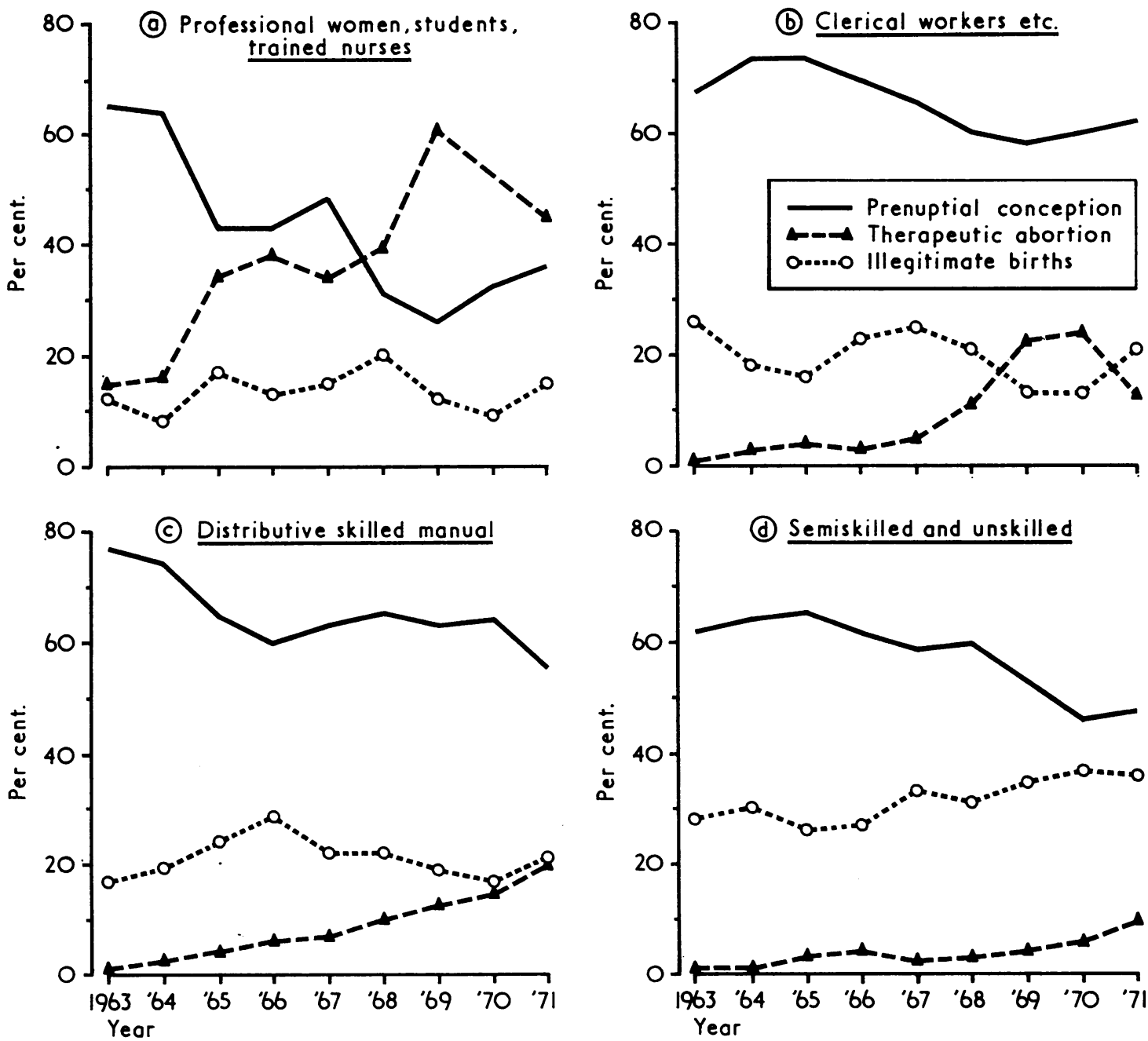

Fig. 2. Outcome of first pregnancies to women single at conception, by occupational group, 1961-71.

illegitimate births this is not so in all social groups (defined by occupation). The unmarried with the highest therapeutic abortion rate are professional women, students, and trained nurses as a group. In their case the proportion marrying while pregnant has made the most dramatic fall (Fig. 2a). This is the only occupational group in which every year the proportion of therapeutic abortions has been consistently higher than the proportion of illegitimate births.

In the next group (designated clerical workers but including all types of office worker, telephonists, receptionists, etc.) the proportion of pregnancies ending in prenuptial conception has fallen less steeply and the proportion terminated is lower than in the professionally trained group (Fig. 2b). Therapeutic abortions as a percentage of total pregnancies in clerical workers exceeded births only in 1969 and 1970, while in the two lower occupational categories (manual workers) the proportion of illegitimate births has always exceeded the proportion of therapeutic abortions (Fig. 2c, d). Semiskilled and unskilled manual workers have the lowest proportion of therapeutic abortions and the highest proportion of illegitimate births of any of the four occupational groups.

In all except the professionally trained, marriage following on pregnancy is still by far the most 
usual outcome. This was so in the professionally trained until the Abortion Act came into force when the proportion of prenuptial conceptions fell dramatically. In $196960 \%$ of all pregnancies in this group were being terminated, a much higher proportion than in the other three groups. If it is true that the more educated are trendsetters in behaviour it is interesting to note that after this peak in 1969 the proportion of their pregnancies being aborted has fallen steeply while that of prenuptial conceptions and illegitimate births has increased. The same trends are apparent in 1971 in the clerical worker group but not so far among manual workers.

It has always been the policy of the Family Planning Clinic to see any woman attending for advice irrespective of marital state. Nevertheless until the late sixties few single women attended and those who did were nearly all about to be married (Table VII). The increase in illegitimate births and abortions constrained the clinic in 1968 to offer as a matter of policy a premarital service, and after women could make their own approach to the clinic without being referred the numbers attending rose rapidly. At the beginning of $1972,45 \%$ of all new attenders were single women and of these only one-fifth were engaged to be married. Although the women came from all occupational groups over half were students, mainly from the University where the Student Health Service does not prescribe contraceptives. Nearly all ask for the pill.

At the beginning of the sixties few Aberdeen women had an adequate knowledge of the physiology of sex and reproduction. Although some sex education had been given in the schools for many years they had been brought up in conditions which discouraged discussion on such matters. In 1968 as a result of a recommendation of the Grampian Television Schools Advisory Committee Aberdeen became the first area in Britain in which a television series on sex education for use in schools was produced (Gill, Reid, and Smith, 1971). The series, 'Living and Growing', was prepared by an Aberdeen obstetrician, K. J. Dennis (now Professor of Obstetrics and Gynaecology at Southampton) for children aged 10 to 13 and won an international award. The series dealt with the human life cycle in the context of the family unit and made only passing reference to the mechanics of sexual intercourse and no reference at all to contraception, family planning, and sterilization. Gill et al. (1971) report the favourable reactions of parents to the series. It has been shown annually and today most teenagers in Aberdeen will have seen it.

\section{Discussion}

Much of the credit for Aberdeen's achievements in maternal care and birth control must go to the organization of its hospital-centred and integrated maternity service in all its aspects. Even more important is the willingness of far-sighted gynaecologists long ago to sterilize women with large families who were certain that they wanted no more children. Perinatal mortality is high in women of high parity (Baird, 1969a). Aberdeen's perinatal mortality rate reached a new low record in $1971,19 \cdot 5$ per 1,000 births compared with 27 in 1961 . This decrease is undoubtedly partly explained by the cumulative effect of the fall in the proportion of women having a fifth or later pregnancy.

TABle VII

FAMILY PLANNING CLINIC-SINGLE WOMEN NEW ATTENDERS FIRST QUARTER EACH YEAR 1964-72

\begin{tabular}{|c|c|c|c|c|c|c|c|c|c|c|c|}
\hline & & & \multicolumn{9}{|c|}{ January-March } \\
\hline & & & 1964 & 1965 & 1966 & 1967 & 1968 & 1969 & 1970 & 1971 & 1972 \\
\hline 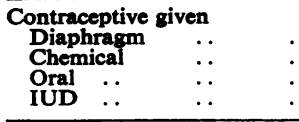 & $\begin{array}{l}\ddot{ } \\
\ddot{*} \\
\dot{ }\end{array}$ & $\begin{array}{l}. . \\
. \\
. \\
\end{array}$ & $\begin{array}{l}\overline{2} \\
-\end{array}$ & $\frac{2}{2}$ & $\frac{1}{5}$ & $\frac{3}{11}$ & $\frac{1}{29}$ & $\underline{\frac{2}{72}}$ & $\begin{array}{r}1 \\
1 \\
95 \\
\end{array}$ & $\begin{array}{r}4 \\
1 \\
141 \\
2\end{array}$ & $\begin{array}{r}10 \\
1 \\
228 \\
-\end{array}$ \\
\hline Total single women & $\cdots$ & $\cdots$ & 2 & 4 & 6 & 14 & 30 & 74 & 97 & 148 & 239 \\
\hline $\begin{array}{l}\text { Marriage arranged before fir } \\
\text { attendance } \\
\end{array}$ & irst & $\cdots$ & 2 & 3 & 5 & 12 & 13 & 33 & 23 & 33 & 48 \\
\hline $\begin{array}{l}\text { Occupation } \\
\begin{array}{l}\text { Student } \\
\text { Teacher, nurse and other } \\
\text { professiona] }\end{array} \\
\begin{array}{l}\text { Clerical and distributive : } \\
\text { Manual } \\
\text { Not stated }\end{array} \text {.. }\end{array}$ & $\begin{array}{l}\cdots \\
\cdots \\
\cdots \\
\cdots\end{array}$ & $\begin{array}{l}\cdots \\
\cdots \\
\cdots \\
\cdots\end{array}$ & $\frac{-}{\bar{z}}$ & $\begin{array}{l}1 \\
1 \\
1 \\
1\end{array}$ & $\begin{array}{r}3 \\
-1 \\
2\end{array}$ & $\begin{array}{l}3 \\
2 \\
2 \\
3 \\
4\end{array}$ & $\begin{array}{r}12 \\
-6 \\
11 \\
1\end{array}$ & $\begin{array}{r}39 \\
6 \\
6 \\
16 \\
7 \\
6\end{array}$ & $\begin{array}{r}55 \\
10 \\
12 \\
16 \\
4\end{array}$ & $\begin{array}{r}92 \\
15 \\
21 \\
18 \\
2\end{array}$ & $\begin{array}{r}133 \\
21 \\
49 \\
35 \\
1\end{array}$ \\
\hline
\end{tabular}


We cannot, of course, know for certain how many couples without the benefit of sterilization might have avoided further pregnancies but this can be estimated (Teper, 1973). Details of nearly all therapeutic abortions are known but it is difficult to assess the contribution of oral contraception to the fall in births. Women prescribed the pill may use it for a few weeks or for many years; they may be casual or consistent in their practice. The emerging pattern seems to be for women to use oral contraception for spacing births but for couples to request sterilization for limiting them. During the many years when sterilization was gradually becoming popular, the Family Planning Clinic was unable to make much progress, largely because the methods available before oral contraception were unacceptable to the majority of the married women the clinic hoped to cater for, particularly those in the lower socio-economic groups. On the other hand, sterilization used to be resorted to almost entirely by women of low socio-economic status who had become debilitated through excessive child-bearing. Both situations have changed and Aberdeen's birth-rate now reflects the cumulative impact of all three aspects of birth control services, family planning, general practitioner activity, and sterilization. First, the pill followed later by a completely free service and the opening of doors to the married and unmarried alike, steadily increased the numbers attending the Family Planning Clinic. Then general practitioners became more actively involved in the provision of contraception. Finally, as women have realized the advantages of sterilization the numbers sterilized increased and the family size of those seeking sterilization has become progressively smaller. The operation is now requested by couples in all sections of society. In the last two years vasectomy has been chosen by many couples in preference to tubal ligation or cautery.

In some respects administrators in Aberdeen have faced fewer problems in developing a comprehensive maternity and birth control service than their counterparts in many other places. One advantage has been a fairly homogeneous and well integrated community. For example, the vast majority of Aberdeen residents have been born and bred in north-east Scotland and are Presbyterian. Most general practitioners have been trained in Aberdeen, they know the hospital consultants and staff personally, and have many opportunities for meeting. All obstetricians in north-east Scotland live in Aberdeen. For over 20 years local authority medical officers and health visitors have attended antenatal and postnatal clinics and have staffed family planning clinics. They are also playing an increasing part in health and sex education, particularly in the schools. Health visitors visiting homes have the opportunity to ensure that no woman remains ignorant of birth control facilities and can advise and encourage those, often older women who may feel that they 'should not bother' their general practitioner with sexual problems.

The services evolved gradually to their present stage and with little overt publicity. It is only recently that the address of the Family Planning Clinic has been listed in the telephone directory and given in the press. There was no local campaign for vasectomy and in 1970 many general practitioners expressed surprise at the numbers of men asking for it. Again, although Aberdeen was known to doctors for its 'liberal' policy on therapeutic abortion many Aberdeen women (particularly married women) who were interviewed for the abortion study in 1968-69 were unaware of this reputation. Aberdeen has never known the pressures which the Abortion Act suddenly brought to the urban centres of the south although the need to accommodate growing numbers of abortions called for a re-allocation between obstetrical and gynaecological beds. This again was facilitated by the unified service in the area, and also by the consensus of opinion among Aberdeen obstetricians and gynaecologists that such accommodation must be made.

Although the number of legitimate pregnancies terminated has more than trebled over the 11 years, therapeutic abortions still account for only a small proportion of legitimate pregnancies. On the other hand, nearly half of all illegitimate pregnancies now end in therapeutic abortion. In the past most unmarried women who became pregnant married before the birth of the baby and after the Abortion Act this was still so except among professional women and students. Among some families in the lower socio-economic groups pregnancy before marriage tended to be accepted and the baby was brought up in the woman's parental home. Before the mid-sixties comparatively few professionally trained women became pregnant before marriage but since then illegitimate pregnancies have become more common in all social classes (Illsley and Gill, 1968). Gynaecologists accept for abortion a rather higher proportion of the professionally trained than other unmarried women referred to them (Horobin, 1973) but access to abortion is primarily regulated by general practitioners who refer more of the better educated. As it seems 'easier' for this group to obtain an abortion, the fall in the proportion of their abortions since 1969 and the rise in the proportion of their prenuptial conceptions and illegitimate births might indicate that fewer of the 
pregnancies in this group are now 'unwanted'. In view of the numbers of professionally trained unmarried women attending the Family Planning Clinic it seems probable that oral contraception is playing an important part in reducing 'unwanted' pregnancies in this group.

It remains to be seen if the fall in the proportion of abortions in both the professional and clerical workers in 1970-71 is more than a temporary fluctuation (Fig. 2a, b). It may be that general practitioners are beginning to feel that the rising numbers of abortions should be checked. Alternatively, women may be readier to accept unmarried motherhood as prejudice weakens and more help and facilities become available. Crellin, Pringle, and West, 1971), in a national study of illegitimacy, note that more unmarried mothers are now keeping their babies, and medical social workers of the Aberdeen Maternity Hospital also report an increase in the percentage of unmarried mothers who leave hospital with this intention (Bell, 1971; McNeil, 1972).

Experience in Aberdeen shows that there is still misunderstanding and ignorance about conception among girls in every social class and that there is much need for accurate information on sex and sexual relationships for both boys and girls. However desirable it is that parents should instruct their children in such an emotionally sensitive area we have to accept that many are ill-equipped to do so precisely because their own parents all too often failed in this respect. If we are to break this vicious circle the main burden of sex instruction for the time being must fall on professional educators and the factual content of their instruction must go beyond the physiology of sex and reproduction and include detailed information on contraception in the context of responsible sexual behaviour.

It might be expected from the policies pursued in Aberdeen, sterilization, abortion, and free contraceptives, that the goal of 'every pregnancy a wanted pregnancy' would be in sight. Disappointingly, the data show that unplanned and unwanted pregnancies are still occurring in considerable numbers in both married and unmarried women. The period studied, however, has seen great changes, not only in medical techniques and contraceptive methods, but also in society, especially in the role of women. These changes which have made it difficult to predict trends in sexual behaviour and marriage are gathering momentum and present us with a formidable task. For the present hope lies in greater co-ordinated efforts in education, the promotion of services, and the removal of administrative delays, e.g., the waiting list for female sterilization. It is of paramount importance that all sexually active women are encouraged to use contraception and are not deterred by real or presumed condemnatory attitudes on the part of professionals from obtaining the method most appropriate in individual circumstances. Financial barriers should certainly be removed, but their removal alone is unlikely to stimulate the unmotivated to use contraception. A major problem is that we know so little about motivation in matters of sexuality and reproduction. At least our data suggest that it is unlikely that any less comprehensive approach to fertility control than that pursued in Aberdeen will succeed in reducing significantly the number of 'unwanted' pregnancies.

\section{SUMMARY}

This article reports on nearly all pregnancies occurring in the city of Aberdeen in the years 1961-71 (births and therapeutic and spontaneous abortions) and on male and female sterilization, and the use of contraceptives. Aberdeen's coordinated and comprehensive maternity and contraceptive services have made it possible to collect these unique data for a defined community. The outcome of pregnancies has been affected by several innovations during the decade, the introduction of oral contraception and the intra-uterine device, laparoscopic sterilization, vasectomy, the Abortion Act, and the removal of charges for contraceptives and of the requirement to be referred to the Family Planning Clinic. The pattern of outcome differs for legitimate and illegitimate pregnancies, which are therefore considered separately. Nearly half of all first pregnancies now occur before marriage and their outcome in women in different occupational groups is discussed. The cumulative effect of a sterilization policy during 25 years has probably been the most significant factor in the fall in perinatal mortality to a new low record in 1971 and has contributed to Aberdeen's low birth rate. The data show, however, that although the birth rate is about replacement level the objective of 'every pregnancy a wanted pregnancy' is far from being achieved.

We wish to thank Sir Dugald Baird, Professor I. MacGillivray, Dr. W. H. Fullerton, Mr. G. W. Horobin, and other colleagues for their helpful comments in the preparation of this paper. We gratefully acknowledge the cooperation received from the Local Authority Health Department (Dr. I. A. G. MacQueen) and in particular from Dr. E. Steiner, who not only kindly provided data on the Family Planning Clinic but generously commented on its interpretation. We also thank the Aberdeen surgeons for the data on vasectomies. 


\section{REFERENCES}

BAIRD, D. (1965). A fifth freedom? Brit. med. J., 2, 1141. (1969a). Perinatal mortality. Lancet, 1, 511.

(1969b). An area maternity service. Lancet, 1, 515. (1971). The obstetrician and society. The Galton Lecture, 1970. J. biosoc. Sci., Suppl. 3, p. 93.

BeLL, E. (1971). Personal communication.

Crellin, E., Pringle, M. L. K., and West, P. (1971). Born Illegitimate, Social and Educational Implications. A Report by National Children's Bureau. National Foundation for Educational Research in England and Wales, Slough.

Gill, D. G., ReID, G. D. B., and SMITH, D. M. (1971). Sex education, press and parental perceptions. Hlth Educ. J., 30, 2.
HoRoBIN, G. W. Ed. (1973). Experience with Abortion: A Case-Study of North-East Scotland. Cambridge University Press (in press).

IllsLeY, R., and Gill, D. G. (1968). Changing trends in illegitimacy. Soc. Sci. Med., 2, 415.

McNeIL, M. (1972). Personal communication.

Medical Officer of Health Report for the Year 1971, CITY OF AbERDEen.

MiLNe, G. P. (1971). Spontaneous and septic abortions in the City of Aberdeen, 1958-68. J. biosoc. Sci., 3, 93.

TEPER, S. (1973). Personal communication.

Tномpson, B., and BAIRD, D. (1969). Follow-up of 186 sterilised women. Lancet, 1, 1023.

- and ILlSLEY, R. (1969). Family growth in Aberdeen. J. biosoc. Sci., 1, 23. 